NISTIR 7964

\title{
Benefits and Costs of Commissioning: A Case Study Analysis
}

Stanley W. Gilbert

http://dx.doi.org/10.6028/NIST.IR.7964 
NISTIR 7964

\section{Benefits and Costs of Commissioning: A Case Study Analysis}

Stanley Gilbert

Applied Economics Office

Engineering Laboratory

http://dx.doi.org/10.6028/NIST.IR.7964

October 2013

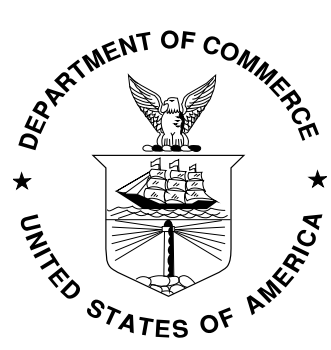

U.S. Department of Commerce Penny Pritzker, Secretary

National Institute of Standards and Technology Patrick D. Gallagher, Under Secretary of Commerce for Standards and Technology and Director 
Certain commercial entities, equipment, or materials may be identified in this document in order to describe an experimental procedure or concept adequately. Such identification is not intended to imply recommendation or endorsement by the National Institute of Standards and Technology, nor is it intended to imply that the entities, materials, or equipment are necessarily the best available for the purpose. 


\begin{abstract}
Commissioning is a "quality assurance process for the design, construction and operation of buildings." Specifically, Building Commissioning is a process of auditing buildings to help them operate with greater efficiency in accomplishing their intended purpose. This typically includes improvements in energy usage, reductions in operation and maintenance costs, improvements in occupant comfort, and reductions in potential future liability.

This report estimates the Benefit-to-Cost Ratio of commissioning-related energy savings for buildings in the International Commissioning Cost-Benefit and Persistence Database. It does so in accordance with ASTM Standards while taking into account the decay of cost savings and the time value of money. Almost all buildings in the database had a Benefit-to-Cost Ratio greater than one. Most had Internal Rates of Return of greater than $100 \%$. Assuming that the buildings in the database are representative of commercial buildings in general, then nearly all commercial buildings can benefit from Commissioning.

Predictors of commissioning-related non-energy savings are evaluated by estimating which task implemented as part of the Commissioning process correlates with the desired outcome for five nonenergy benefits in the Annex 47 Database. Due to the small size of the data set, results should be considered tentative. The most reliable results are for reduction in O\&M Costs. Benchmarking, Development of a Commissioning Plan, and the Development of an Energy Model are associated with a reduction in O\&M Costs.
\end{abstract}

Keywords: Commissioning; Commercial Buildings; Benefit-to-Cost Ratio; Economic Analysis; Standards 


\section{Acknowledgements}

The author wishes to thank all those who contributed so many excellent ideas and suggestions for this report. They include Natascha Milesi-Ferretti and Steven Bushby, of the Energy and Environment Division of the Engineering Laboratory (EL) at the National Institute of Standards and Technology (NIST) for financial support, and considerable technical assistance for this report. Appreciation is also extended to Dr. Robert E. Chapman and Dr. Joshua Kneifel for their comments and suggestions, and to Ms. Shannon Takach for her assistance in preparing the manuscript for review and publication. The report has also benefitted from the review and technical comments provided by Dr. Nicos Matrys of EL's Materials and Structural Systems Division. As always, all remaining errors are the responsibility of the author. 


\section{Contents}

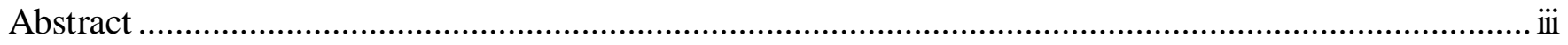

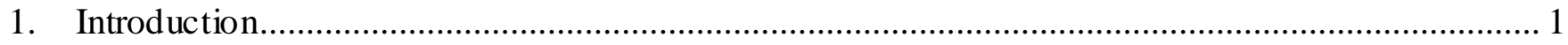

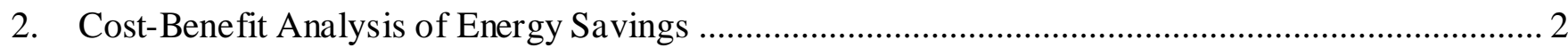

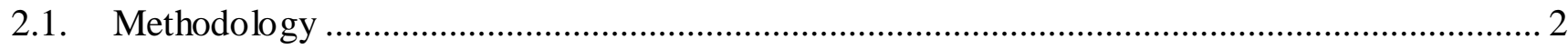

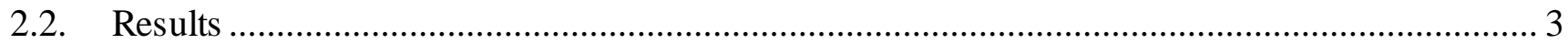

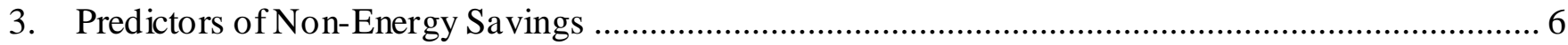

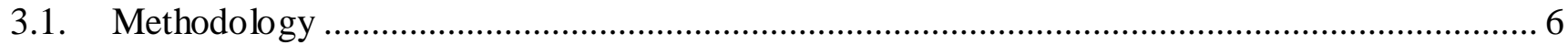

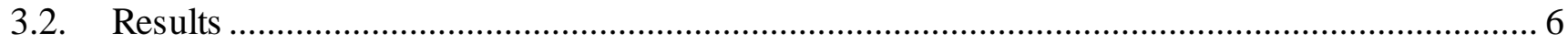

4. Summary and Recommendations for Further Research ..................................................... 9

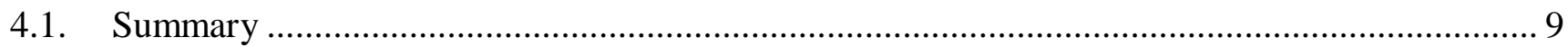

4.2. Recommendations for Further Research........................................................................ 9

\section{Figures}

Figure 1: Histogram of Number of Issues for Buildings in the Annex 47 Report.................................. 2

Figure 2: Empirical estimated probability densities for Internal Rate of Return.................................. 3

Figure 3: Cumulative Distribution of Log Benefit-to-Cost Ratios. . .................................................. 5 


\section{Tables}

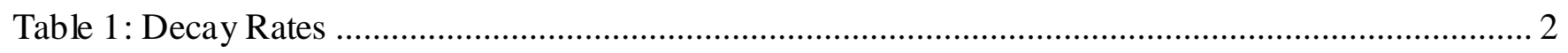

Table 2: Example randomly generated cash flows for Wehner Building at Texas A\&M ....................... 3

Table 3: Median IRR and Benefit-to-Cost ratio by project ...................................................... 4

Table 4: Questions Analyzed for predictors of non-energy savings. .............................................. 6

Table 5: Tasks potentially performed as part of commissioning studies. ......................................... 7

Table 6: The probability that the Task has no effect on the outcome analyzed................................... 7

\section{List of Acronyms}

BCR Benefit-to-Cost Ratio

IRR Internal Rate of Return

O\&M Operations and Maintenance 


\section{Introduction}

Commissioning is a "quality assurance process for the design, construction and operation of buildings." Specifically Building Commissioning is a process of auditing buildings to help them operate with greater efficiency in accomplishing their intended purpose. This typically includes improvements in energy usage, reductions in operation and maintenance costs, improvements in occupant comfort, and reductions in potential future liability.

Recently, the Energy Conservation for Buildings and Community Systems Program, Annex 47: CostEffective Commissioning for Existing and Low Energy Buildings produced a report on "Commissioning Cost-Benefit and Persistence of Savings." The objective of the report was to estimate the payback period for commissioning and estimate the persistence of energy savings for commissioning.

As part of the process of generating the Annex 47 report the task force compiled an International Commissioning Cost-Benefit and Persistence Database. That database contains data on 47 buildings from seven different countries (Belgium, Canada, Germany, Japan, the Netherlands, Norway, and the United States). For each building the database sought to include project information (including cost data), information on energy usage and cost savings, non-energy benefits, issues found in each building in the study, and corrective measures taken. Data collected was incomplete for all buildings in the database.

This report set out to use the Annex 47 database to accomplish two goals. First, this report assesses the cost-effectiveness of Commissioning in accordance ASTM Standards maintained by ASTM Subcommittee E06.81 on Building Economics, and published as part of the ASTM Standards on Building Economics ${ }^{2}$. Second, this report attempts to identify predictors of non-energy savings from Commissioning.

Based on the results, almost all buildings in the database had a Benefit-to-Cost Ratio (BCR) greater than one, indicating that commissioning was cost-effective. Most had Internal Rates of Return (IRR) of greater than $100 \%$. For non-energy savings, Benchmarking, Development of a Commissioning Plan, and the Development of an Energy Model are associated with a reduction in O\&M Costs.

In what follows, Section 2 evaluates the cost-effectiveness of Commissioning for the buildings in the Annex 47 Database. Section 3 attempts to identify predictors of non-energy savings from Commissioning. Section 4 concludes with a summary and recommendations for future research.

\footnotetext{
1 “Commissioning Cost-Benefit and Persistence of Savings”, a Report of Cost-Effective Commissioning of Existing and Low Energy Buildings. Directed by the Energy Conservation in Buildings and Community Systems (ECBCS) Program.

${ }^{2}$ ASTM International. 2012. “ASTM Standards on Building Economics.” $7^{\text {th }}$ Edition. ASTM International. West Conshohocken, PA.
} 


\section{Cost-Benefit Analysis of Energy Savings}

The first goal this report seeks to accomplish is to compute the $\mathrm{BCR}^{3}$ and $\mathrm{IRR}^{4}$ of the commissioningrelated energy savings for buildings in the Annex 47 Database. Costs used for this section were the reported costs for Commissioning for each project, while total Benefits were the total of all monetary energy-related benefits reported for each project.

\subsection{Methodology}

Table 1: Decay Rates

\begin{tabular}{|l|rcr|}
\hline & \multicolumn{1}{|c|}{$\begin{array}{c}\text { Savings } \\
\text { Remaining }\end{array}$} & Years & Decay Rate \\
\hline Texas A\&M & $83 \%$ & 2 & $9.12 \%$ \\
Texas A\&M & $92 \%$ & 2 & $4.04 \%$ \\
SMUD & $81 \%$ & 4 & $5.13 \%$ \\
Oregon-Elec. & $89 \%$ & 5 & $2.30 \%$ \\
Oregon-Gas & $3 \%$ & 5 & $50.00 \%$ \\
Colo-Elec. & $83 \%$ & 7 & $2.63 \%$ \\
Colo-Demand & $86 \%$ & 7 & $2.13 \%$ \\
Colo-Gas & $100 \%$ & 7 & $0.00 \%$ \\
CA & $75 \%$ & 4 & $6.94 \%$ \\
\hline
\end{tabular}

Data are drawn from the Annex 47 Data Set and report.

Of the 47 projects in the database, 22 reported both costs and energy-related benefits. However, one of them almost certainly contains a reporting error. For that reason, it was deleted from further consideration, leaving 21 projects for the analysis.

Benefits were assumed to accrue as a result of the correction of "Issues." "Issues" are problems identified as part of the commissioning process. Issues commonly include things like sensor problems or sub-optimal setpoints for temperature control.

Each issue was assumed to equally contribute to the total benefits. So, for example, the Wehner building at Texas A\&M reported approximately $\$ 48,000$ in annual savings, and reported five Issues corrected. So, for the purpose of this study, it was assumed that each Issue contributed $\$ 9,600$ in savings.

Figure 1 shows a histogram of the number of Issues reported for buildings analyzed in this portion of the report. The average number of Issues for buildings that record issues is 6.26. Three buildings have no Issues recorded. Projects where Issues were not reported were assumed to have corrected ten Issues.

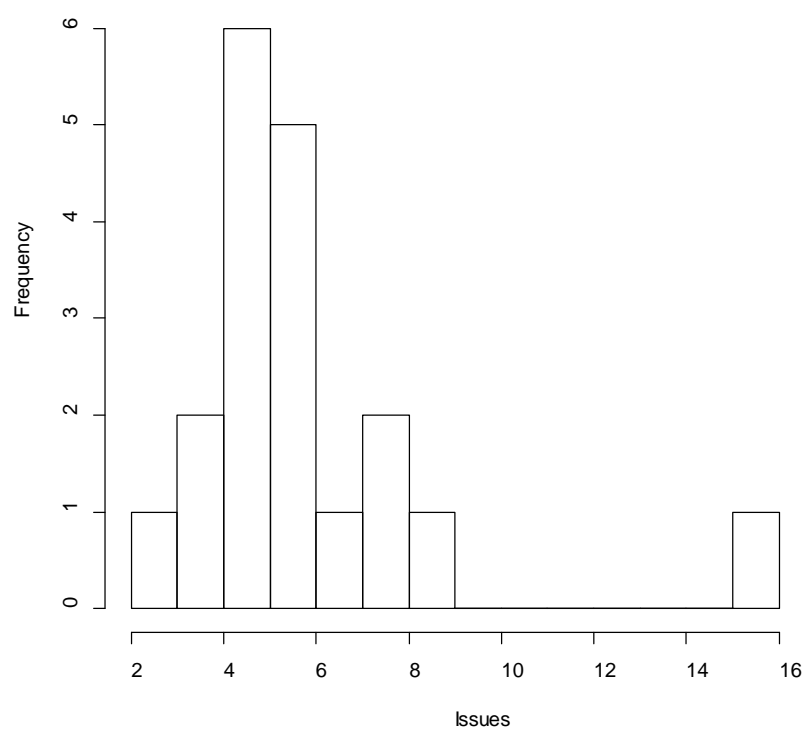

Issues were assumed to revert to their "uncorrected" state with a probability of $\delta$ per year. The decay rate $(\delta)$ was based on the reports of persistence of benefits from the "Annex 47" report. Computed decay rates for the projects for which persistence was analyzed are listed in Table 1.

\footnotetext{
${ }^{3}$ ASTM Standard E964-06, 2010, “Standard Practice for MeasurAnnex 47 Report

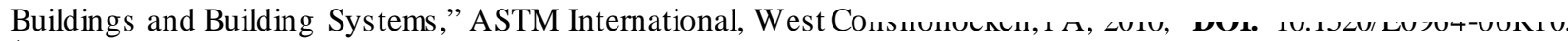
${ }^{4}$ ASTM Standard E4157-06, 2010, “Standard Practice for Measuring Internal Rate of Return and Adjusted Internal Rate of Return in Buildings and Building Systems,” ASTM International, West Conshohocken, PA, 2010, DOI: 10.1520/E105706R10.

${ }^{5}$ This is the Texas A\&M results excluding the results for the G. R. White Coliseum and the Kleberg Building, which had large degradations in performance due to one or two major failures.
} 
Based on this data, a $5 \%$ decay rate (which is close to the median decay rate) was used for all computations below. Monte Carlo methods ${ }^{6}$ were used to compute BCRs and IRRs using a large number of simulations. For each simulation, failures were randomly generated and distributed by year. Then costs and benefits by year were computed. Finally, based on the assumed (stochastically generated) cash flow, IRR and BCR were computed. This was done for five different study periods $(5,10,15,20$, and 30 years). The BCRs were computed for four different discount rates (3\%, $5 \%, 7 \%, 10 \%$, and $15 \%$ ). An example for a single instance is shown in Table 2. In the table "Failures" represents the number of corrected Issues that fail in that year. "Net Benefit" represents the value of energy savings for that year after accounting for the cumulative number of corrected Issues that have failed up to that point. "Discounted" represents the Present value of the net benefits using the $5 \%$ discount rate. For each project-study-period combination, 100000 simulations were generated.
Table 2: Example randomly generated cash flows for Wehner Building at Texas A\&M-Ten Year study period-5 \% Discount Rate

\begin{tabular}{|c|c|c|c|}
\hline Year & Failures & $\begin{array}{c}\text { Net } \\
\text { Benefit }\end{array}$ & Discounted \\
\hline 0 & 0 & $-\$ 66423$ & $-\$ 66423$ \\
\hline 1 & 1 & $\$ 43255$ & $\$ 41196$ \\
\hline 2 & 0 & $\$ 43255$ & $\$ 39234$ \\
\hline 3 & 0 & $\$ 43255$ & $\$ 37365$ \\
\hline 4 & 0 & $\$ 43255$ & $\$ 35586$ \\
\hline 5 & 1 & $\$ 38449$ & $\$ 30126$ \\
\hline 6 & 0 & $\$ 38449$ & \$ 28691 \\
\hline 7 & 2 & $\$ 28837$ & $\$ 20494$ \\
\hline 8 & 0 & $\$ 28837$ & $\$ 19518$ \\
\hline 9 & 0 & $\$ 28837$ & \$ 18588 \\
\hline 10 & 0 & $\$ 28837$ & $\$ 17703$ \\
\hline
\end{tabular}

\subsection{Results}

Median IRR and BCR for the ten-year study period and $5 \%$ discount rate are listed in Table 3 . The highlighted projects are the only ones with a negative payoff (i.e., were not cost-effective).

Estimated cumulative probability density (estimated using the 'density' function in the ' $R$ ' statistical computing environment ${ }^{7}$ ) for return on investment based on the 21 remaining projects are shown in Figure 2. As study period increases, the percentage of projects that fall below any cutoff decreases. However, once the study period reaches ten years the difference between IRRs becomes minimal.

Based on the estimated densities, about $15 \%$ of projects can be expected to have an IRR of less than $5 \%$, about $17.5 \%$ of projects can be expected to have an IRR of less than $15 \%$, and about $19.5 \%$

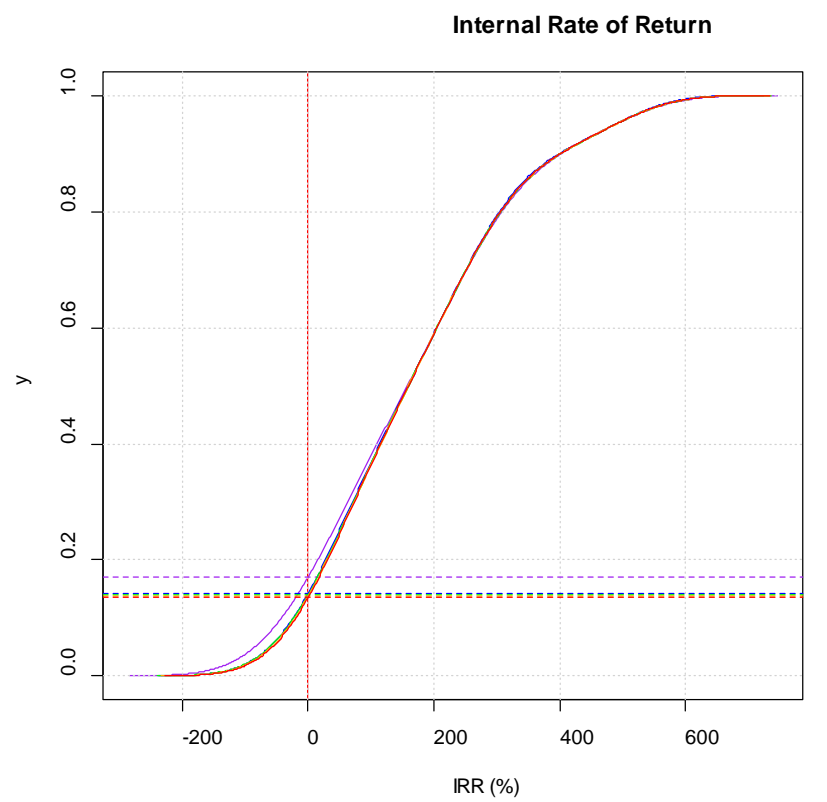

Figure 2: Empirical estimated probability densities for Internal Rate of Return

\footnotetext{
${ }^{6}$ ASTM Standard E1369-11, 2011, "Standard Guide for Selecting Techniques for Treating Uncertainty and Risk in the Economic Evaluation of Buildings and Building Systems,” ASTM International, West Conshohocken, PA, 2011, DOI: 10.1520/E1369-11.

${ }^{7}$ R Core Team, 2013, “R: A Language and Environment for Statistical computing.” R Foundation for Statistical Computing. Vienna Austria.
} 
of projects can be expected to have an IRR of less than $25 \%$.

Also computed are Cumulative Distribution Functions for the BCR for all the discount rates examined (see Figure 3). As with IRR, once the study period exceeds ten years, the probability that a project fails to pay off changes very little.

In each of the sub-figures, the horizontal lines show the probability that the BCR falls below one for each study period. In each sub-figure, the probability that the BCR falls below one is highest for the 5 year study period. The probabilities become difficult to distinguish for all longer study periods.

The probabilities that the BCR falls below one also increase as the discount rate increases, but not by much. The probabilities increase because a higher discount rate reduces the value of the future savings, thus reducing the value of commissioning the building. However, since the BCR for most buildings are so high, the increase in discount rate does not increase the probability that BCR falls below one by much.

Table 3: Median Internal Rate of Return and Benefit-to-Cost ratio by project using a 10 year study period and a $5 \%$ discount rate. Projects that have a negative pay off are highlighted.

\begin{tabular}{|l|l|r|r|r|r|}
\hline Country & Project & $\begin{array}{c}\text { Commissioning } \\
\text { Cost }\end{array}$ & \multicolumn{1}{c|}{$\begin{array}{c}\text { Annual } \\
\text { Savings }\end{array}$} & \multicolumn{1}{c|}{$\begin{array}{c}\text { Median } \\
\text { IRR }\end{array}$} & \multicolumn{1}{c|}{$\begin{array}{c}\text { Median } \\
\text { BCR }\end{array}$} \\
\hline Norway & Hotel 1 & $\mathrm{kr} \mathrm{110} \mathrm{000}$ & $\mathrm{kr} \mathrm{570} \mathrm{421}$ & $516 \%$ & 31.63 \\
\hline Norway & Hotel 2 & $\mathrm{kr} \mathrm{110} \mathrm{000}$ & $\mathrm{kr} \mathrm{275} \mathrm{000}$ & $246 \%$ & 15.28 \\
\hline Norway & Hotel 3 & $\mathrm{kr} \mathrm{110} \mathrm{000}$ & $\mathrm{kr} \mathrm{376} \mathrm{750}$ & $333 \%$ & 20.76 \\
\hline Norway & Hotel 4 & $\mathrm{kr} \mathrm{110} \mathrm{000}$ & $\mathrm{kr} \mathrm{257} \mathrm{400}$ & $225 \%$ & 14.21 \\
\hline Norway & Material Teknisk Bygget & $\mathrm{kr} \mathrm{33000}$ & $\mathrm{kr} \mathrm{99667}$ & $301 \%$ & 18.24 \\
\hline United States & Blocker & $\$ 77324$ & $\$ 80678$ & $98 \%$ & 6.38 \\
\hline United States & Eller & $\$ 99050$ & $\$ 112047$ & $105 \%$ & 6.86 \\
\hline United States & G. Rollie White & $\$ 49525$ & $\$ 124080$ & $246 \%$ & 15.48 \\
\hline United States & Harrington Tower & $\$ 27344$ & $\$ 63696$ & $229 \%$ & 14.39 \\
\hline United States & Kleberg & $\$ 59054$ & $\$ 278331$ & $468 \%$ & 28.81 \\
\hline United States & Koldus & $\$ 41894$ & $\$ 61802$ & $142 \%$ & 9.02 \\
\hline United States & Richardson Petroleum & $\$ 44541$ & $\$ 126079$ & $279 \%$ & 17.49 \\
\hline United States & Vet Med Center Addition & $\$ 52314$ & $\$ 101892$ & $194 \%$ & 11.79 \\
\hline United States & Wehner & $\$ 66423$ & $\$ 48063$ & $67 \%$ & 4.47 \\
\hline United States & Allied Plaza & $\$ 71693$ & $\$ 26065$ & $28 \%$ & 2.24 \\
\hline United States & Mark O. Haftield Federal Courthouse & $\$ 180554$ & $\$ 92962$ & $43 \%$ & 3.11 \\
\hline Japan & Kobe Kanden Building & $¥ 10800000$ & $¥ 390113$ & $-19 \%$ & 0.22 \\
\hline Japan & Nakanoshima 3-chome DHC & $¥ 19800000$ & $¥ 260876$ & $-29 \%$ & 0.08 \\
\hline Japan & CEPCO Atsuta Sales Office & $¥ 10480000$ & $¥ 2828432$ & $18 \%$ & 1.63 \\
\hline Canada & Palais des congrès de Montréal & $\$ 199300$ & $\$ 309942$ & $146 \%$ & 9.41 \\
\hline Canada & CETC-Varennes & $\$ 90000$ & $\$ 36831$ & $33 \%$ & 2.48 \\
\hline
\end{tabular}


Discount Rate $=3 \%$

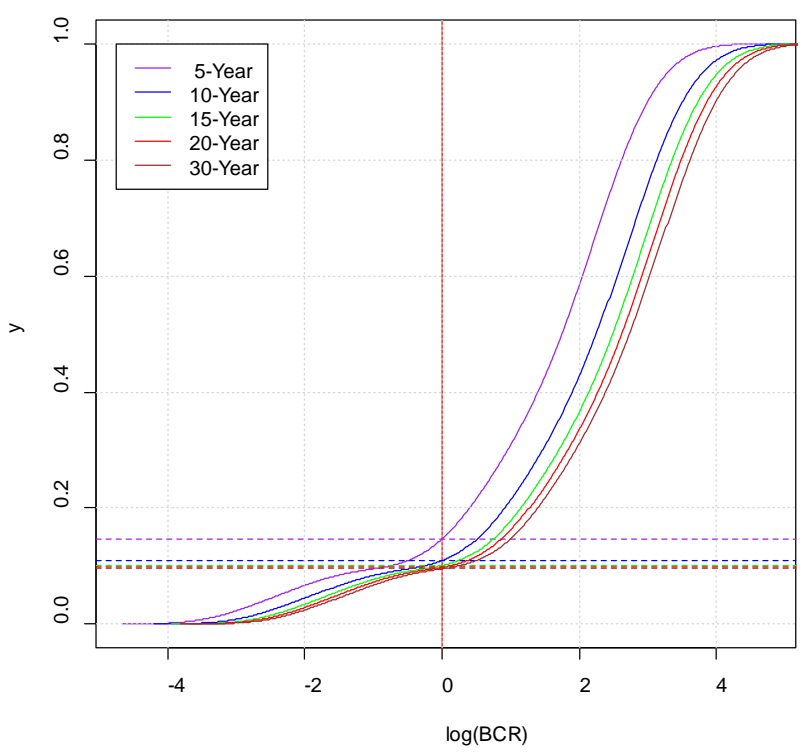

Discount Rate $=10 \%$

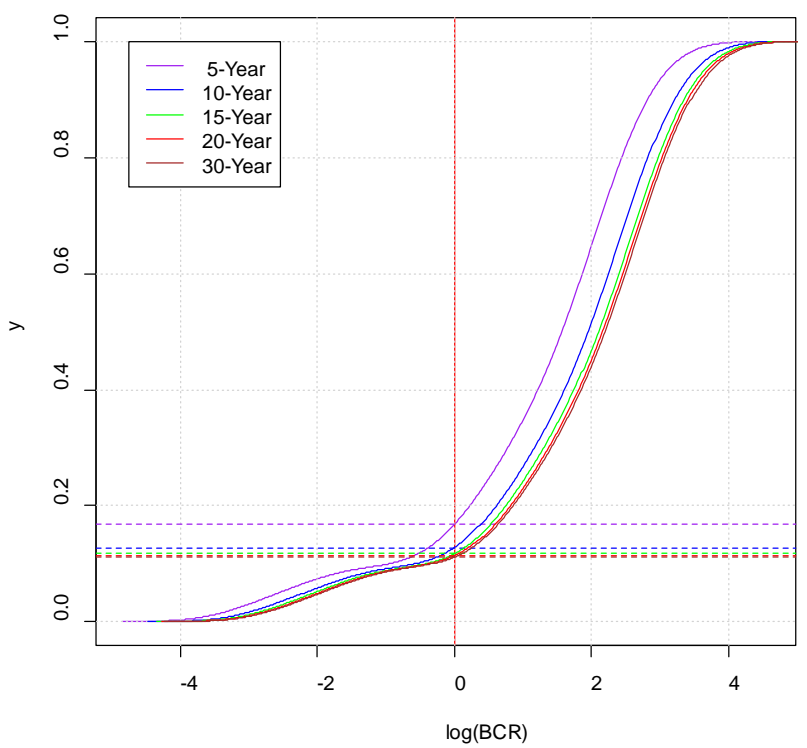

Discount Rate $=7 \%$

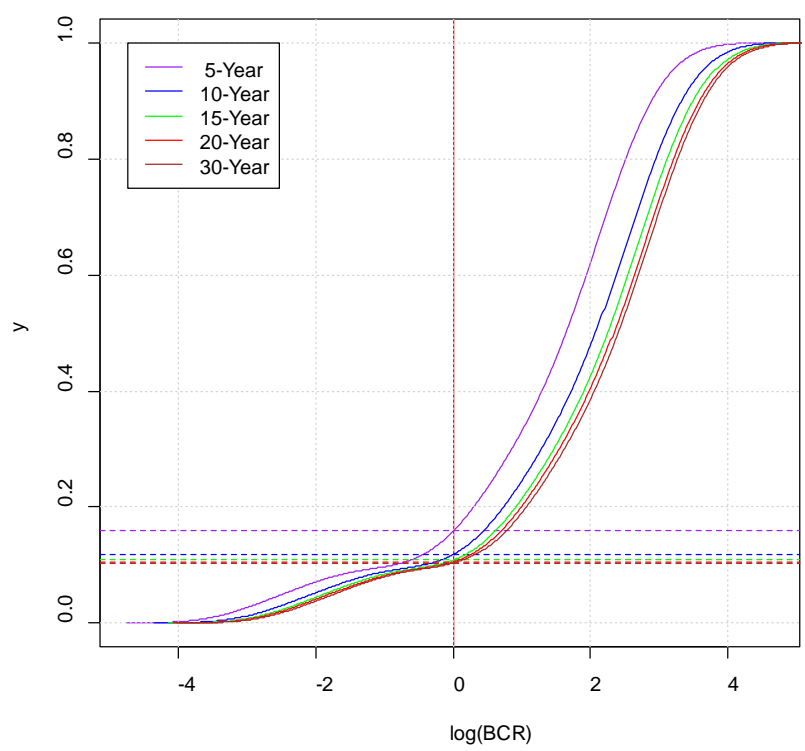

Discount Rate $=15 \%$

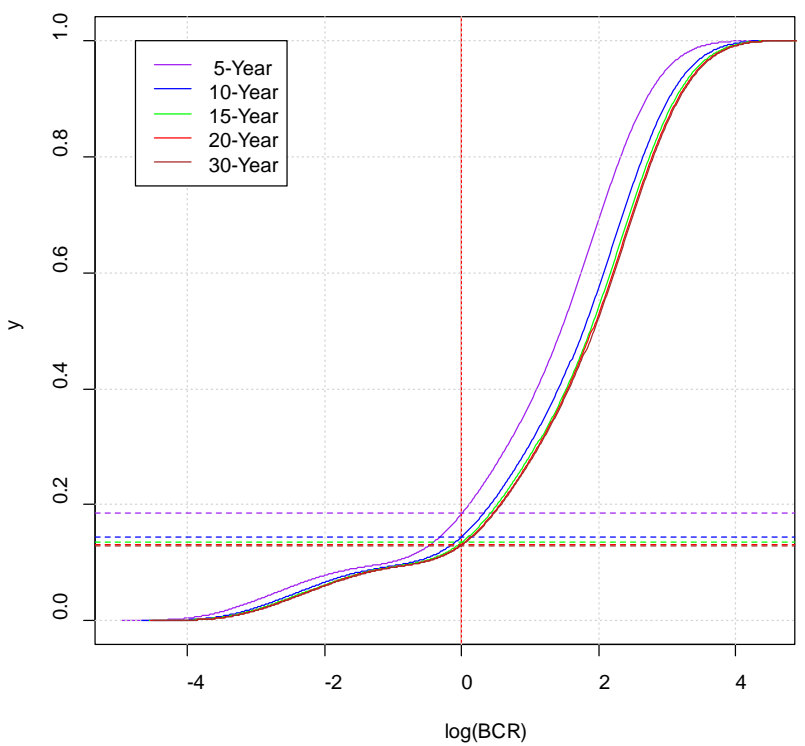

Figure 3: Cumulative Distribution of Log Benefit-to-Cost Ratios. The upper left figure is for a discount rate of $3 \%$. The upper right figure is for a discount rate of $7 \%$. The lower left figure is for a discount rate of $10 \%$. And the lower left figure is for a discount rate of $15 \%$. 


\section{Predictors of Non-Energy Savings}

The Annex 47 Database includes questions asking about a variety of non-energy related benefits that could result from Commissioning a building. For the most part the questions are qualitative: that is, they ask whether a specific benefit resulted from the Commissioning study, and make no effort to quantify the benefit. The Database includes 26 questions about non-energy benefits. 21 of the questions are qualitative Yes / No questions about the existence of some benefit. The remaining five questions ask to quantify the value of those benefits. The questions were only answered for some of the buildings with a different quantity of answers for different questions. Valuation questions were only answered for O\&M costs, and not for enough buildings to be able to reliably estimate cost savings.

Table 4: Questions Analyzed for predictors of non-energy savings.

\begin{tabular}{|l|l|c|c|}
\hline Item Label & Question & Responses & $\begin{array}{c}\text { Yes } \\
\text { Responses }\end{array}$ \\
\hline Staff & $\begin{array}{l}\text { Do O\&M staff report increased ability to operate and } \\
\text { maintain the building as a result of Commissioning? }\end{array}$ & 11 & 6 \\
\hline Costs & $\begin{array}{l}\text { Were ongoing operations and maintenance costs } \\
\text { reduced as a result of Commissioning? }\end{array}$ & 18 & 8 \\
\hline Air & $\begin{array}{l}\text { Was indoor air quality improved as a result of } \\
\text { Commissioning? }\end{array}$ & 11 & 6 \\
\hline Productivity & $\begin{array}{l}\text { Was occupant productivity improved as a result of } \\
\text { Commissioning? }\end{array}$ & 11 & 7 \\
\hline Liability & Was liability reduced as a result of Commissioning? & 11 & 5 \\
\hline
\end{tabular}

This report attempts to identify qualitatively what predicts a positive outcome for a specific type of nonenergy savings. In order to estimate that outcome, two characteristics must hold. First, there must be enough answers to the question to produce a reliable result. Second there must be a sufficient variety of answers (that is, both yes and no answers) to distinguish between characteristics that predict yes outcomes and ones that do not.

\subsection{Methodology}

Five of the non-energy savings items from the list were selected for further analysis. The five are listed in Table 4.

The Tasks that were performed in the Commissioning process were used as predictors of whether a Yes response was given to each of the questions above. The Tasks analyzed and their descriptions are listed in Table 5. There were simply not enough responses to analyze the Tasks simultaneously, so each was regressed individually against each question using a standard Logit analysis.

\subsection{Results}

The results shown in Table 5 are the probabilities that the Task listed has no effect on the outcome analyzed. So, smaller numbers indicate a stronger relationship (i.e., there is a greater likelihood of a 
beneficial effect). Cells shown in Red and Blue are significant at the $10 \%$ level and $25 \%$ level, respectively. The latter group should be interpreted as Tasks-Outcome pairs that should be analyzed in more detail if more data become available.

Table 5: Tasks potentially performed as part of commissioning studies.

\begin{tabular}{|c|c|}
\hline Task & Description \\
\hline Benchmarking & Benchmarking \\
\hline Calculate Savings & Calculate energy cost savings for findings \\
\hline Capital Improvements & Implement capital improvements \\
\hline Commissioning Plan & Develop a Commissioning Plan \\
\hline Diagnostic Tools & Use of Diagnostic Tools and Cx Automation Techniques \\
\hline Energy Model & Building energy modeling/simulation \\
\hline Final Report & Final Comissioning Report \\
\hline Document Findings & Document master list of findings \\
\hline Manual & Develop systems manual/recommissioning manual \\
\hline Monitor Persistence & Monitor implemented measures for persistence of benefits \\
\hline O\&M Improvements & Implement operations and maintenance (O\&M) improvements \\
\hline Project Requirements & Document owner's project requirements \\
\hline Report & Present a findings and recommendations report \\
\hline Trend Analysis & Trend Analysis (for example, EMCS, data logging, etc.) \\
\hline Update Documentation & Update system documentation after implementation \\
\hline Utility Bill Analysis & Utility Bill Analysis \\
\hline Verify Energy Savings & Monitor and verify energy savings \\
\hline
\end{tabular}

The greatest significance occurs for Operation and Maintenance Costs, which, not coincidentally, have the most available responses. Benchmarking, Developing a Commissioning Plan, and Development of an Energy Model all are predictors of a reduction in O\&M Costs.

Table 6: Results show the probability that the Task listed has no effect on the outcome analyzed. Cells shown in Red are significant at the $10 \%$ level. Cells shown in blue are "significant" at the $25 \%$ level.

\begin{tabular}{|l|r|r|r|r|r|}
\hline Task & \multicolumn{1}{|c|}{ Staff } & Costs & Air & Productivity & Liability \\
\hline Benchmarking & $74.06 \%$ & $5.97 \%$ & $38.26 \%$ & $31.67 \%$ & $31.67 \%$ \\
Calculate Savings & $81.92 \%$ & $14.84 \%$ & $15.76 \%$ & $55.80 \%$ & $38.26 \%$ \\
\hline Capital Improvements & $99.67 \%$ & $18.85 \%$ & $99.65 \%$ & $66.11 \%$ & $62.40 \%$ \\
Commissioning Plan & $31.67 \%$ & $6.87 \%$ & $31.67 \%$ & $99.61 \%$ & $31.67 \%$ \\
\hline Diagnostic Tools & $38.26 \%$ & $81.41 \%$ & $99.58 \%$ & $89.83 \%$ & $81.92 \%$ \\
Energy Model & $62.40 \%$ & $8.34 \%$ & $88.66 \%$ & $99.66 \%$ & $88.66 \%$ \\
\hline Final Report & $38.26 \%$ & $67.19 \%$ & $38.26 \%$ & $31.67 \%$ & $15.76 \%$ \\
Document Findings & $38.26 \%$ & $21.74 \%$ & $74.06 \%$ & $6.75 \%$ & $31.67 \%$ \\
\hline Manual & $99.67 \%$ & $80.02 \%$ & $99.65 \%$ & $66.11 \%$ & $88.66 \%$ \\
Monitor Persistence & $14.15 \%$ & $67.19 \%$ & $31.67 \%$ & $22.35 \%$ & $74.06 \%$ \\
\hline O\&M Improvements & $38.26 \%$ & $11.72 \%$ & $38.26 \%$ & $15.76 \%$ & $81.92 \%$ \\
Project Requirements & $99.65 \%$ & $19.12 \%$ & $99.60 \%$ & $89.83 \%$ & $81.92 \%$ \\
\hline Report & $81.92 \%$ & $99.54 \%$ & $81.92 \%$ & $48.22 \%$ & $99.60 \%$ \\
Trend Analysis & $15.76 \%$ & $99.54 \%$ & $81.92 \%$ & $99.71 \%$ & $39.85 \%$ \\
\hline Update Documentation & $99.67 \%$ & $99.52 \%$ & $99.65 \%$ & $99.65 \%$ & $88.66 \%$ \\
Utility Bill Analysis & $74.06 \%$ & $11.72 \%$ & $74.06 \%$ & $81.92 \%$ & $31.67 \%$ \\
\hline Verify Energy Savings & $81.92 \%$ & $67.19 \%$ & $74.06 \%$ & $6.75 \%$ & $74.06 \%$ \\
\hline
\end{tabular}

Similarly, Documenting Findings, and Verification of Energy Savings were predictors of reporting 
Productivity improvements for the building occupants. None of the other questions are significant predictors of outcomes. Note that these results should be treated very cautiously. The nature of the data makes these results very weak, and additional data would significantly improve the results. 


\section{Summary and Recommendations for Further Research}

\subsection{Summary}

This report estimates the BCR of commissioning-related energy savings for buildings in the Annex 47 Database. It does so while taking into account the decay of cost savings and the time value of money. Almost all buildings in the database had a BCR greater than one. Most had an IRR of greater than $100 \%$. Compared to other investments, a $100 \%$ return on investment is exceptionally high. Assuming that the buildings in the database are representative of commercial buildings in general, then nearly all commercial buildings can benefit from Commissioning.

Predictors of commissioning-related non-energy savings are evaluated by estimating which tasks implemented as part of the Commissioning report correlate with the desired outcome for five non-energy benefits in the Commissioning Database. Due to the small size of the data set results should be considered tentative. Best results are for reduction in O\&M Costs. Benchmarking, Development of a Commissioning Plan, and the Development of an Energy Model are associated with a reduction in O\&M Costs. Results for the other non-energy savings should be understood as suggestive rather than definitive.

\subsection{Recommendations for Further Research}

Commissioning studies frequently cite comfort as one of the objectives of Commissioning work. However, the Annex 47 database does not include any information on comfort. If it were possible to place a value on the improvements in comfort level, we could get a better sense of the valued added from Commissioning.

The following methodology could aid in valuing the improvements in comfort level. The basic approach is to estimate the average cost to individuals of being in locations with less-than-optimal temperatures. This data would then be used to estimate the hedonic ${ }^{8}$ cost to people in a building where temperature is maintained at a suboptimal level.

Even though commissioning is done in commercial buildings, the best source of information for how people value (dis)comfort would be the temperature they maintain in their own homes where they control the thermostat versus the cost. Therefore, we would need the following individual-level data for households:

- Thermostat settings over time

- Approximate location (sufficiently detailed to determine average temperature throughout the year).

- Heated Floor Area

Additional information that would be very helpful in estimating a value of comfort would be:

\footnotetext{
${ }^{8}$ Rosen, S. 1974. “Hedonic Prices and Implicit Markets: Product Differentiation in Pure Competition.” The Journal of Political Economy: 34-55.
} 
- Number of Stories

- $\quad$ Age of structure

- Number of people in the household

It would be possible to substitute similar data for businesses for household data, but the interpretation of the results would be slightly different and the estimation would be potentially more difficult.

The basic approach consists of assuming the people have a utility function of the form:

$$
U=u(v)-h(T)
$$

where $v$ is other consumption, $T$ is ambient indoor temperature, and $h$ and $u$ are functions.

A number of approaches can be taken, but the simplest is to assume that $\mathrm{u}$ is approximately linear over the relevant range of consumption. Then utility becomes:

$$
U=m-c(T)-h(T)
$$

Where $m$ is household income, and $c$ is the cost of setting indoor air temperature to $T$.

We would expect thermostats to be set in advance, and changed relatively rarely. On that basis, all of these terms should be understood as being in expectation.

Cost will depend on a number of factors, and will likely need to be estimated. Taking that into account, the utility function would be written as:

$$
U=m-c(T ; x, \beta)-h(T)
$$

where $x$ represents information known about the structure that affects the cost of heating and cooling and $\beta$ are regression parameters that will be estimated. The function $h$ would be estimated nonparametrically.

We assume that people are utility maximizers, so the problem people solve is:

$$
\max _{T}(m-c(T ; x, \beta)-h(T))
$$

Solution to that problem will be $T$ such that the following equation holds:

$$
f(T ; x, \beta)=-c^{\prime}(T ; x, \beta)-h^{\prime}(T)=0
$$

Or

$$
\widehat{T}=f^{-1}(0 ; x, \beta)
$$

In practice, we would assume that the actual thermostat temperature selected was;

$$
T^{*}=f^{-1}(0 ; x, \beta)+\varepsilon
$$

Where $\varepsilon$ is a random variable. 
This then reduces to two problems. First, estimating the expected cost of setting indoor air temperature to $T$, and second estimate the function $h$ non-parametrically. Most of the data needs above are directed toward answering the first question. The estimation is unambiguously non-linear, but the techniques for doing so are well established. Provided an adequate data set can be obtained, this should be relatively straightforward. 